\title{
Development Of A Mathematical Model For Calculating Accumulated Solid Waste: An Experimental And Statistical Sampling
}

\author{
Taiwo Alare ${ }^{1}$ and Kehinde Alare ${ }^{2}$ \\ ${ }^{1}$ Federal University of Technology Akure \\ ${ }^{2}$ Ladoke Akintola University of Technology
}

October 12,2020

\begin{abstract}
In newest development, waste is being refined into a biofuel or being recycled. This is to say lots of works has done to turn or transform waste into useful materials. Waste management has being an important factor in community development. Therefore, data base must be developed to know the amount of waste accumulated or generated over a given period of time. Taken into consideration the incremental factor, degradable waste ratio and burning and recycle reduction factor. This paper look for a mathematical formula that can be used to generate data for amount of solid waste accumulated over time for geographical location in respect of mass.
\end{abstract}

\section{Hosted file}

Mathematical Model For Calculating Accumulated Waste.pdf available at https://authorea. com/users/366637/articles/486324-development-of-a-mathematical-model-for-calculatingaccumulated-solid-waste-an-experimental-and-statistical-sampling 